\title{
Public health crises: the development of a consensus document on their management in Spain
}

T Rodrigo (trodrigo@aspb.es) ${ }^{1}$, J A Caylà', the Working Group of the Network of Public Health Research Centres (RCESP)²

1. Epidemiology Service, Agencia de Salud Pública de Barcelona (Public Health Agency), Barcelona, Spain

2. The members of the working group are listed at the end of the article

Rodrigo T, Caylà JA, the Working Group of the Network of Public Health Research Centres (RCESP). Public health crises: the development of a consensus document on their management in Spain. Euro Surveill. 2011;16(15):pii=19841. Available online: http://www.eurosurveillance.org/ViewArticle.aspx?Articleld=19841

Several public health crises in Europe have led to sustained outbreaks, political problems, or have generated social alarm. For this reason, a nationwide study was conducted in Spain with the objective to determine which public health events provoke the most frequent crises, to reach a consensus regarding the appropriate actions to be taken when responding to public health crises, and to provide recommendations for their management. The events which had most frequently provoked crises between 1999 and 2004 were identified. A consensus was obtained by public health experts from the 17 Autonomous Regions of Spain and the National Epidemiological Centre using the RAND/ UCLA method which combines the Nominal Groups and Delphi techniques. Legionellosis, foodborne diseases, severe acute respiratory syndrome (SARS), bovine spongiform encephalopathy (BSE), bioterrorism, meningococcal meningitis, tuberculosis, heat waves, and influenza epidemics were found to be cause for most public health crises. In Spain, $75 \%$ of the crises identified by senior public health experts from the Autonomous Regions involved infectious diseases. Factors triggering a crisis included the type of disease, social alarm, population affected, and the course of action taken by public institutions and reporting in the media. There was consensus that correct information, qualified personnel, availability of standardised protocols for investigation and control, information distribution, and setting up of 'crisis offices' were actions with a positive effect regarding crisis resolution. Appropriate management of outbreaks or other situations being perceived as a risk to health can mitigate or even contain the generation of public health crises.

\section{Introduction}

Each year, one of five World Health Organization (WHO) member states experiences some type of event (disease outbreak, environmental calamity, etc.) that threatens the health of its people [1]. It has been suggested that two billion people worldwide face health threats because they are at risk of, or exposed to, public health crises. Thus, preparation, mitigation, response, and control of such crises are public health priorities [1]. Nonetheless, decisions aimed at resolving them are often taken without the active participation of those responsible for the implementation of implicated programmes [2].

Spain has experienced several public health crises in recent years, some of which were solved rapidly and adequately, while others were not. The tardiness or failure to resolve some of them has lead to sustained outbreaks, difficult political situations, or inappropriate information by the press, and thus generated undue social alarm. Crises of public health require a rapid assessment of measures necessary for their resolution to accurately assign and manage resources [3]. When confronted with a crisis, many politicians are often rather concerned with its public consequences instead of investigating its causes. In response, pressure is put on epidemiologists to find causes and implement control measures rapidly that can complicate the investigation of an event.

In Spain, in 2005, a study involving public health experts from all Spanish Autonomous Regions was conducted with the intention to establish criteria for good practice in the management of epidemics (infectious diseases or not) or other emerging crisis situations in public health. The study objectives were (i) to determine which events provoke the most frequent public health crises, (ii) to reach a consensus regarding the appropriate actions to be taken when responding to events with an impact on public health, and (iii) to provide recommendations for their management.

\section{Methods}

For the purpose of the study, a public health crisis was defined as an event or a related series of events that overwhelm the capacity of the public health services to maintain the health of a community [4]. We identified events which had most often provoked health crises in Spain between 1999 and 2004 through expert consultation and a database search.

\section{Study participants}

A letter was sent to general directors of public health services in the 17 Autonomous Regions asking for 
information about the five largest or most frequent crises experienced in the study period. Furthermore, the Autonomous Regions and the National Epidemiological Centre (CNE, Centro Nacional de Epidemiología) were asked to nominate a technical expert for collaboration with the study leader to ensure reliable information and to achieve a consensus for actions at national level.

\section{Database and other sources searched}

Databases: Medline, Biblioteca Virtual en Salud (BVS), Scientific Electronic Library Online- (Scielo), Literatura Latinoamericana y del Caribe en Ciencias de la Salud (LILACS), Pan American Health Organization (PAHO) and the World Health Organization's library database (WHOLIS), Cochrane Library Plus and Embase.

Web pages: World Health Organization, Eurosurveillance, Morbidity and Mortality Weekly Report, Elsevier, and Scirus. Other: Google, Yahoo, Doyma Editors, online archives of important national newspapers (ABC, El Periódico de Catalunya, La Vanguardia, El País, El Mundo, Diario Médico), Informe Quiral [5], and other

\section{TABLE 1}

Most frequent events/diseases provoking public health crises according to responses from senior public health experts from Autonomous Regions, Spain 2005

\begin{tabular}{|c|c|}
\hline Public health crises aetiology & Number of autonomous regions \\
\hline Legionellosis outbreaks & 13 \\
\hline Foodborne diseases & 10 \\
\hline SARS & 9 \\
\hline BSE & 6 \\
\hline Bioterrorism & 6 \\
\hline Meningococcal meningitis & 5 \\
\hline Drinking water contamination ${ }^{a}$ & 5 \\
\hline Tuberculosis & 4 \\
\hline Heat waves & 4 \\
\hline Brucellosis & 3 \\
\hline Avian influenza & 3 \\
\hline Hepatitis $C^{b}$ & 3 \\
\hline Dioxins & 2 \\
\hline Prestige oil-spillc & 2 \\
\hline Tumours $^{d}$ & 2 \\
\hline Pneumococcal pneumonia & 1 \\
\hline Surgical aspergillosis ${ }^{b}$ & 1 \\
\hline Influenza & 1 \\
\hline Chemical poisoning & 1 \\
\hline Mumps & 1 \\
\hline Measles & 1 \\
\hline Rubella & 1 \\
\hline Non-specific gastroenteritis & 1 \\
\hline Hepatitis A & 1 \\
\hline
\end{tabular}

BSE: Bovine spongiform encephalopathy; SARS: Severe acute respiratory syndrome.

a Either by infectious pathogens such as norovirus, Shighella, and

Cryptosporidium or toxins such as arsenic, and lead.

b Nosocomial infection.

c The only oil-spill disaster in Spain during the study period.

${ }^{\mathrm{d}}$ Benign or malignant, due to proximity to magnetic fields. sources, such as Epidemiological Bulletins of the public health services of the Autonomous Regions.

Keywords used to identify crisis included: epidemic, outbreak, intoxication, foodborne disease, public health crisis, public health crisis management, heat wave, Prestige (the only oil-spill disaster in Spain during the study period), bovine spongiform encephalopathy (BSE) and mad cow disease. The selection of keywords was based on the most frequent crisis experienced by the 17 Autonomous Regions.

\section{RAND/UCLA Appropriateness method}

We implemented the RAND/UCLA Appropriateness method, which is based on scientific evidence and combines the Nominal Groups and Delphi techniques [6].

\section{Nominal Group technique}

According to the Nominal Group technique a group of experts discusses, and eliminates ideas to finally agree upon a prioritised list of ideas $[7,8]$. Our Nominal Group consisted of 17 experts responsible for epidemiological surveillance of epidemic outbreaks of transmissible and non-transmissible diseases in each of the respective Autonomous Regions and one expert from the CNE. In addition, the study coordinator and study leader were part of the group with a voting right. Consensus was considered as an agreement of at least $60 \%$ among the expert group members in line with the methodology described by Amezcua et al. [9].

\section{Delphi qualitative evaluation technique}

To reach a consensus on the most suitable actions for crisis management, the Delphi qualitative evaluation technique was considered as the most appropriate method $[9,10]$. This technique consists of interviewing a group of experts or panellists using a series of questionnaires to identify future topics of interest. In our study, experts participated in a series of interactive sessions, organised in rounds to eventually create a high level of consensus. The panellists were the same experts as in the initial Nominal Group and all participated in each round.

Based on the panellists' answers to the initial questionnaire, a new questionnaire was created for a second round. The order of items presented was based on the percentage of agreement achieved in the first round. The questionnaire was then sent to the panellists with a request to arrange the items numerically by order of perceived priority and a coincidence of at least $60 \%$ was considered a consensus [7]. After that, a final consensus list was created for the items for which consensus had been reached.

Email was used for the communication between panellists and the study leader for sending and receiving the questionnaires for each round, and for queries or feedback. In addition, telephone calls were used for clarification of remaining doubts. The role of the study coordinator was to supervise the work of the panellists 
and the study leader and to organise the meeting of the Nominal Group together with the latter.

\section{Results}

According to the representatives of the Autonomous Regions the most frequent diseases or events leading to public health crises involved outbreaks of legionellosis, foodborne diseases, SARS, BSE, bioterrorism, meningococcal meningitis, drinking water contamination (either by infectious pathogens such as norovirus, Shighella, and Cryptosporidium or toxins such as arsenic and lead), tuberculosis, and heat waves (Table 1). According to the results, $75 \%$ of the diseases or events provoking crisis in public health were of infectious aetiology, while $25 \%$ were due to other causes.

Our results show that events that cause or trigger public health crises vary considerably and that different bibliographic search strategies generate different results (Table 2 ).

The database search yielded a total of 106 articles; most frequently associated with public health crisis were: BSE (32 articles; 30\%), foodborne diseases (14;
$13 \%)$, influenza (8; $8 \%)$, meningococcal meningitis (6; 6\%), SARS and nosocomial infections (5; $5 \%$ ), for acquired immunodeficiency syndrome (AIDS), tuberculosis, legionellosis, bioterrorism, and avian influenza less than five articles were retrieved.

The search of online archives produced 3,454 reports mentioning most often the Prestige oil-spill $(1,160$; $34 \%)$, BSE (984; 29\%), heat waves (332; 10\%), legionellosis (307; 9\%), foodborne diseases (197; 6\%), SARS (128; 4\%), influenza and AIDS ( $3 \%$ and $2 \%$ respectively) in connection with public health crisis.

The review of all issues of Informe Quiral yielded 18,448 reports on health. AIDS $(2,638 ; 14 \%)$, smoking $(2,177$; $12 \%)$, legionellosis (1,826; 10\%), BSE (1,660; $9 \%)$, drug abuse $(1,550 ; 8 \%)$, eating conditions (particularly obesity) $(1,513 ; 8 \%)$, cancer $(1,457 ; 8 \%)$, foodborne diseases $(1,291 ; 7 \%)$ and SARS $(1,218 ; 7 \%)$ featured as most frequent topics, followed by bioterrorism, dioxin, tumours (benign or malignant) possibly from proximity to magnetic fields, the Prestige oil-spill, avian influenza and nosocomial infections which were mentioned in less than $5 \%$ of articles.

\section{TABLE 2}

Literature research on reported causes of public health crises from 1999-2004 by source, Spain 2005

\begin{tabular}{|c|c|c|c|}
\hline Aetiology public health crises & $\begin{array}{c}\text { Databases } \\
\mathrm{N}(\%)\end{array}$ & $\begin{array}{l}\text { Other on-line archives }{ }^{\mathrm{a}} \\
\mathrm{N}(\%)\end{array}$ & $\begin{array}{c}\text { Informe Quiral } \\
\mathrm{N}(\%)\end{array}$ \\
\hline Legionellosis & $3(3)$ & $307(9)$ & $1,826(10)$ \\
\hline Foodborne diseases & $14(13)$ & $197(6)$ & $1,291(7)$ \\
\hline SARS & $5(5)$ & $128(4)$ & $1,218(7)$ \\
\hline BSE & $32(30)$ & $984(29)$ & $1,660(9)$ \\
\hline Influenza & $8(8)$ & $93(3)$ & - \\
\hline AIDS & $4(4)$ & $69(2)$ & $2,638(14)$ \\
\hline Bioterrorism & $2(2)$ & $10(0)$ & $812(4)$ \\
\hline Prestige oil-spill ${ }^{\mathrm{b}}$ & - & $1,160(34)$ & $277(2)$ \\
\hline Meningococcal meningitis & $6(6)$ & - & - \\
\hline Nosocomial infections & $5(5)$ & - & $203(1)$ \\
\hline Tuberculosis & $4(4)$ & - & - \\
\hline Avian influenza & $2(2)$ & $29(1)$ & $277(2)$ \\
\hline Heat waves & - & $332(10)$ & $184(1)$ \\
\hline Hepatitis C ${ }^{c}$ & - & $24(1)$ & - \\
\hline Smoking & - & - & $2,177(12)$ \\
\hline Drug abuse & - & - & $1,550(8)$ \\
\hline Eating conditions $^{d}$ & - & - & $1,513(8)$ \\
\hline Cancer & - & - & $1,457(8)$ \\
\hline Dioxins & - & - & $406(2)$ \\
\hline Tumore & - & - & $350(2)$ \\
\hline Other pathologies ${ }^{f}$ & $21(20)$ & $121(4)$ & 609 (3) \\
\hline Total & $106(100)$ & 3,454 (100) & $18,448(100)$ \\
\hline
\end{tabular}

AIDS: Acquired immunodeficiency syndrome; BSE: Bovine spongiform encephalopathy; SARS: Severe acute respiratory syndrome.

a Google, Yahoo, Doyma Editors, newpapers (ABC, El Periódico de Catalunya, La Vanguardia, El País, El Mundo and Diario Médico) and

Epidemiological Bulletins.

${ }^{\mathrm{b}}$ The only oil-spill disaster in Spain during the study period.

c Nosocomial infection.

d Particularly obesity.

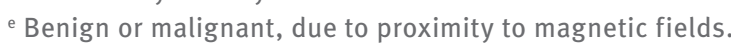

${ }^{f}$ Chickenpox, hepatitis B, chemical poisoning etc. 
The factors which influence the development of a public health crisis according to the panellists in the first round are listed in Table 3. In the second round, the factors which influence in order of priority were: (i) the type of disease or risk, (ii) social alarm generated and the population's perception, (iii) the population affected, (iv) measures taken by public health authorities, and (v) attitudes of the mass media (Table 4).

Participants agreed on a number of points that are relevant for a fast resolution of public health crisis: correct information, adequate qualification of technical personnel, availability of standardised protocols for investigation and control, availability of channels for case notification, communication between surveillance experts and healthcare services and evaluation of progress during resolution and of the final outcome. However, delay in starting an investigation, lack of coordination, disagreement between experts and politicians, lack of resources, and lack good communication were seen as hindering crisis resolution (Table 5).

\section{Discussion}

Our findings and the resulting recommendations which are drawn from Spanish public health experts' consensus could be of particular interest to public health authorities and politicians involved in the management of epidemics or public health crises caused by both communicable and non-communicable diseases. Literature research did not reveal similar exercises attempting to reach consensus for recommendations on how to deal with public health crises. Thus the lack of comparison with similar research represents a limitation of our work. The selected keywords were based on the most frequent crises experienced by the 17 Autonomous Regions. This may have lead to an overrepresentation of the incidents included. However, we believe that the results are valid and can be generalised for the Spanish context because of our intensive literature research. Furthermore, our nominal group included 17 experts from all Autonomous Regions in

\section{TABLE 3}

Factors influencing the occurrence of public health crises, according to senior public health experts from Autonomous Regions (questionnaire first round), Spain 2005

\begin{tabular}{|l|l|}
\multirow{4}{*}{$\begin{array}{l}\text { Factors which influence the occur- } \\
\text { rence of public health crises }\end{array}$} & Public health risks \\
\cline { 2 - 2 } & Social alarm \\
\cline { 2 - 2 } & Perception of the population \\
\cline { 2 - 2 } & Health of the population \\
\cline { 2 - 2 } & Public health actions \\
\hline \multirow{3}{*}{$\begin{array}{l}\text { Positive and negative aspects which } \\
\text { have an influence in the resolution } \\
\text { of public health crises }\end{array}$} & $\begin{array}{l}\text { Intervention by public health } \\
\text { experts }\end{array}$ \\
\cline { 2 - 2 } & Other factors \\
\hline
\end{tabular}

a Discordant opinion, lack of coordination, new or limited knowledge of disease, outstanding relevance internationally.
Spain and one expert from the National Epidemiological Centre.

The Delphi technique is used to reach consensus in large population groups that cannot meet regularly, or when the consensus pertains to a sensitive topic that cannot be debated publicly [11]. We used the technique in our study considering the distance separating the panellists and the difficulty associated with face to face meetings of the Nominal Group. By combining two techniques (RAND/UCLA Appropriateness method) [6] however, it was possible for the experts to meet and discuss the proposals in a structured manner, and for us to facilitate consensus between disparate perspectives $[9,10]$.

Early detection of an event that can lead to a crisis depends on standardised information systems available for health departments and clinical services to facilitate data management, investigation, and preparation of necessary responses $[12,13]$. A lack of coordination between departments and ministries concerned with their 'own interests' can aggravate a crisis [14].

Management of crisis situations consists of three recognised stages: prevention, preparation of measures to be implemented, and recovery [15]. Thus directors of public health authorities should estimate the impact of emergency situations, set up and implement appropriate actions, be persuasive, and employ organised management [16]. During an emergency situation, preparation and adequate operational capacity are fundamental for a rapid and appropriate response by the public health system $[17,18]$. For future improvement it is important to learn from the mistakes and successes of crisis response [19]. In our study, experts considered measures taken by the health authorities a priority for resolving public health crisis.

Recommendations for the management of public health crises resulting from our expert group consensus are as follows:

- To mitigate factors involved in crisis situations, it is necessary to create in advance guidelines with standardised protocols for investigation and control.

- For a better implementation of prevention and control measures and an appropriate response when facing a public health crisis, the coordination between public health departments and clinical services needs to be improved.

- Communication to the population should not be interrupted. Frequent contact between public health professionals and the media, is crucial.

- Evaluation of progress during crisis resolution and of the final crisis resolution is necessary. Evaluation (internal or external) should help avoid multiple, repetitive or unnecessary activities that could hinder adequate progress in crisis resolution. 
TABLE 4

Factors influencing the occurrence of public health crises, according to senior public health experts from Autonomous

Regions (questionnaire second round), Spain 2005

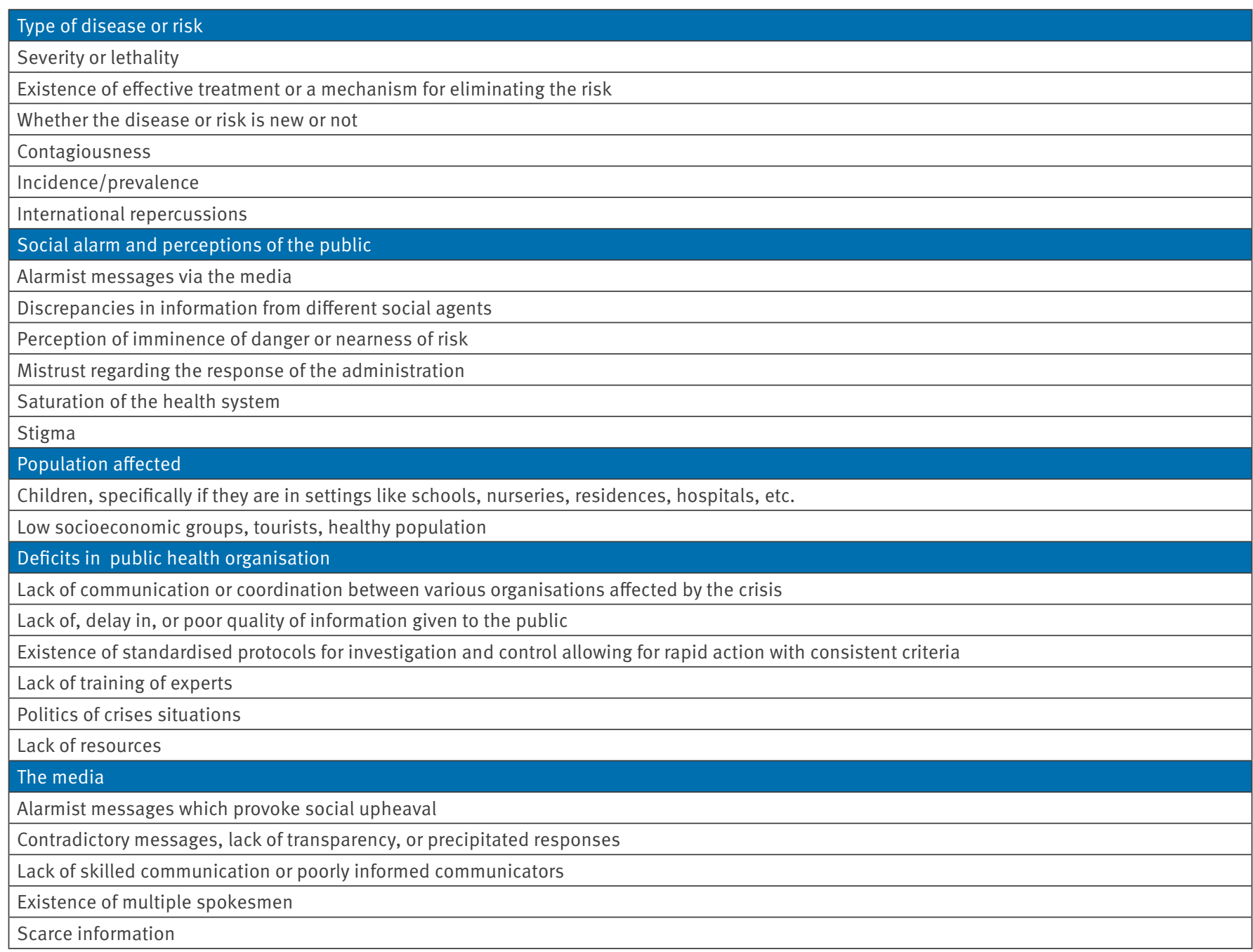

\section{TABLE 5}

Consensus about appropriate actions for the resolution of public health crises, according to senior public health experts from Autonomous Regions, Spain 2005 ${ }^{\mathrm{a}}$

\section{Positive actions}

Correct, timely, and quality information for health professionals, affected populations, and the media

Qualified technical personnel, independent of political powers and with sufficient resources

Preparation of a standardised protocol for investigation and control

Established method of case notification, exchange of information and communication between public health experts and clinics

Arranging a crisis office or technical committee with a coordinator or leader (one or the other depending on type and severity of problem)

Existence of a single spokesman for the media

Evaluation of progress during resolution and of the final outcome

Negative actions

Delay in starting an investigation of the crisis

Lack of coordination among implicated institutions

Disagreement between experts and politicians in decision taking

Lack of technical or economic resources

Lack of knowledge about the related topics

Lack of good communication methods with de means; information excessively technical, lacking transparency, or contradictory

${ }^{a}$ In order of priority: highest priority on top, lowest on bottom. 
- Health policy must establish priorities and directions which ensure the effectiveness and efficiency of interventions.

In conclusion, our study shows that a considerable number of public health crises in Spain involve infectious diseases and that various factors contribute to the occurrence or aggravation of such situations. However, backed up by the literature reviewed and the consensus in the group of senior experts, we believe that public health crises can be mitigated or contained by adequate management following consensus documents that take these factors into account. Public health crises management can be effective if: the information among parties involved (public health experts and clinicians) as well as between these parties and the media is correct, the qualification of technical personnel is adequate, standardised protocols for investigation and control are available, evaluation of progress during the public health crisis resolution and of the final outcome is performed and, finally, if responsibilities are specified and well understood.

Members of the working group of the Network of Public Health Research Centres (RCESP):

R Cano, Centro Nacional de Epidemiología, Madrid, Spain; J M Mayoral, Junta de Andalucía, Sevilla Spain; J Guimbao, Gobierno de Aragón, Zaragoza, Spain; P Alonso, Gobierno del Principado de Asturias, Oviedo, Spain; P Matute, Gobierno de Canarias, Las Palmas de Gran Canaria, Spain; L J Viloria, Gobierno de Cantabria, Santander, Spain; I Rosell, Junta de Castilla y León, Valladolid, Spain; G Gutiérrez; Junta de Comunidades de Castilla-La Mancha, Toledo, Spain; A Domínguez, Generalitat de Catalunya, Barcelona, Spain; M del Mar Álvarez, Junta de Extremadura, Badajoz, Spain; A Malvar, Xunta de Galicia, Santiago de Compostela, Spain; A Galmés, Comunidad Autónoma de las Islas Baleares Palma de Mallorca, Spain; M Perucha, C Quiñones, Gobierno de La Rioja, Logroño, Spain; R Ramírez, Comunidad de Madrid, Madrid, Spain; C Navarro, Región de Murcia, Murcia, Spain; E Ardanaz, Jesús C, Gobierno de Navarra, Pamplona, Spain; M Á García, Gobierno Vasco, Vitoria, Spain; H Vanaclocha, F González, Generalitat Valenciana, Valencia, Spain.

\section{Acknowledgements}

We are grateful to Dr Patricia García de Olalla, Dr Angels Orcau, Dr Cristina Rius and Dr Helena Pañella at the Servicio de Epidemiología de la Agència de Salut Pública de Barcelona for their contributions and comments regarding the design of this study, to Dr Alicia Granados and Dr Josep M. Antó for their constructive criticism which helped to improve this article, and to Dr Teresa Moreno Casbas of the Unidad de Coordinación y Desarrollo de la Investigación en Enfermería del Instituto de Salud Carlos III, Madrid for her collaboration as an expert in qualitative evaluation methods. To Jeanne Nelson at the Servicio de Epidemiología de la Agència de Salut Pública de Barcelona, for her accurate revision of this paper.

\section{References}

1. World Health Organization (WHO). Why is there a need to focus on public health crises? Geneva:WHO. 2011. Available from: www.who.int/hac/about/threeyearplan_focus/en/print.html

2. Lemus JD, Clovis HT, Ruiz PL, Dachs N. Manual de vigilancia epidemiológica. [Epidemiology Surveillance Manual]. Panamerican Health Organization. Regional Office of the World Health Organization. 1996. Spanish. Available from: http:// www.bvsde.ops-oms.org/bvsea/e/fulltext/manual/manual. html\#pro
3. Guha-Sapir D. Rapid assessment of health needs in mass emergencies: review of currents concepts and methods. World Health Stat Q. 1991;44(3):171-81.

4. Pencheon D, Guest C, Melzer D, Muir Gray JA (Editors). Oxford Handbook of Public Health Practice. New York: Oxford University Press. 2006.

5. Vila Casa Foundation. Quiral Reports 1999-2004. Barcelona:Vila Casa Foundation. Available from: http://www. fundaciovilacasas.com/es/proyecto_salud/informe_Quiral

6. Martínez-Sahuquillo Amuedo ME. Métodos de consenso. Uso adecuado de la evidencia en la toma de decisiones. "Método RAND/UCLA". [Consensus methods. Adequate use of evidence for decision making. "RAND/UCLA Method"]. Rehabilitación. 2001;35(6):388-92. Spanish.

7. Pineault R, Daveluy C. La planificación sanitaria. Conceptos , métodos, estrategias. [Healthcare planning. Concepts, methods, strategies ]. Barcelona. Masson. 1987. Spanish.

8. Lacalle JR, Pastor L, Reyes A, Pérez MJ, Álvarez R. Metodología Delphi aplicada a la evaluación de procedimientos diagnósticos y terapéuticos. [Delphi methodology used for the evaluation of diagnostic and therapeutic procedures]. In: Consenso en medicina. Metodología de expertos. [Consensus in medicine. Expert methodology]. Escuela Andaluza de Salud Pública. 1996:53-69. Spanish.

9. Amezcua Martinez M. La entrevista en grupo. Características, tipos y utilidades en investigación cualitativa. [Group interview. Characteristics, types, and uses of qualitative research]. Enf Clin. 2003;13(2):112-17.

10. Lindstone HA, Turoff M (Editors). The Delphi method: techniques and applications: Reading, MA, Addison-Wesley. 1975;3-12.

11. Moreno-Casbas T, Martín-Arribas C, Orts-Cortés I, CometCortés $\mathrm{P}$; Investén-isciii Co-ordination and Development of Nursing Research Centre. Identification of priorities for nursing research in Spain: a Delphi study. J Adv Nur. 2001;35(6):857-63.

12. Broome CV, Loonsk J. Public Health Information Network-improving early detection by using a standards-based approach to connecting public health and clinical medicine. MMWR Morb Mortal Wkly Rep. 2004;53 Suppl:199-202.

13. Reddy MC, Paul SA, Abraham J, McNeese M, DeFlitch C, Yen J. Challenges to effective crisis management: using information and communication technologies to coordinate emergency medical services and emergency department teams. Int J Med Inform. 2009;78(4):259-69.

14. Chess C, Clarke L. Facilitation of risk communication during the anthrax attacks of 2001: the organizational backstory. Am J Public Health, 2007;97(9):1578-83.

15. Grant SE, Powell D. Crisis Response \& Communication Planning Manual. Ontario Ministry of Agriculture, Food and Rural Affairs. Ontario. 1999.

16. Tachibanai T, Takemura S, Sone T, Segami K, Kato N. Competence necessary for Japanese public health center directors in responding to public health emergencies. Nippon Koshu Eisei Zasshi, 2005;52(11):943-56.

17. Johnson MM, Bone EA, Predy GN. Taking care of the sick and scared: a local response in pandemic preparedness. Can J Public Health. 2005;96(6):412-4.

18. Nicoll A, Editorial team. Preventing and controlling disease outbreaks in a complex emergency situation: discussion of the tsunami aftermath. Euro Surveill. 2005;10(13):pii=2673. Available from: http://www.eurosurveillance.org/ViewArticle. aspx?Articleld $=2673$

19. Gérvas I, Hernández-Aguado I. Aciertos y errores en la gestión de las crisis de salud pública en España. [Progress and errors in public health crisis management in Spain]. Gac Sanit. 2009;23(1):67-71. Spanish. 